PHARMACOKINETICS

\title{
Population pharmacokinetics of high dose ibuprofen in cystic fibrosis
}

\author{
I Arranz, A Martín-Suárez, J M Lanao, F Mora, C Vázquez, A Escribano, M Juste, J Mercader, \\ E Ripoll
}

See end of article for authors' affiliations

......................

Correspondence to: Dr I Arranz, Biochemical Service, Ramón y Cajal Hospital, Madrid, Spain; marranz@hrc.insalud.es

Accepted 22 April 2003
Aims: To evaluate ibuprofen population pharmacokinetics in a large series of data collected in children with cystic fibrosis (CF) treated with high doses of ibuprofen (59 patients; 2-18 years), and to identify the main causes responsible for the considerable interindividual variability in ibuprofen serum levels.

Methods: Blood samples were collected during routine clinical care; serum ibuprofen concentrations were determined by HPLC. Fitting of the concentration/time data to a one compartment kinetic population model was performed by a non-linear mixed effect regression method.

Results: Body weight, dose, and ibuprofen dosage form (lysinate salt or the free acid form), for elimination clearance $(\mathrm{CL} / \mathrm{F})$; and body weight, dose, and fasting status for the apparent distribution volume $(\mathrm{Vd} / \mathrm{F})$ proved to be the covariates with influence in the model. The four factors identified helped to explain part of the interindividual variability observed, but the remaining unexplained variability made therapeutic drug monitoring absolutely essential. b buprofen is a safe and effective orally administered nonsteroidal anti-inflammatory drug. High dose ibuprofen administered consistently over four years has been shown to slow deterioration in pulmonary function in children over 5 years of age with mild $\mathrm{CF}$, without unacceptable adverse effects. ${ }^{1-4}$

We studied the population pharmacokinetics of ibuprofen in children with CF with a view to identifying the main factors responsible for the considerable variability observed in ibuprofen serum levels. ${ }^{16-8}$ Knowledge of these factors should allow prediction of the initial ibuprofen doses required to obtain therapeutically optimum results.

\section{MATERIALS AND METHODS}

\section{Patients and sampling schedule}

The population pharmacokinetics of ibuprofen were studied in a multicentre survey of 59 children from three hospitals over 1-5 years. All patients were treated with high dose ibuprofen in two different tablets formulations: ibuprofen lysinate (Doctril, Abello Farmacia Lab) and ibuprofen in free acid form (Neobrufen, Knoll Lab). Blood specimens were obtained before and every 30 minutes after ibuprofen administration for three hours. When the free acid form was administered, in some cases sampling was prolonged to four or five hours post-dose, in order to better assess the elimination phase. The initial ibuprofen doses (15-25 mg/ $\mathrm{kg}$ ), calculated according to the recommendations of Konstan and colleagues, ${ }^{16}{ }^{6}$ were later modified to obtain therapeutic peak concentration values (Cmax) of 50-100 mg/l. ${ }^{2}$ Blood sampling was repeated after changes in the dose or ibuprofen dosage form administered, patient's weight, and clinical supervision. Table 1 shows the demographic and clinical data of the patients.

\section{Analytical technique}

Samples of frozen serum from the different hospitals were packed in dry ice and sent to the clinical laboratory, where they were stored at $-40^{\circ} \mathrm{C}$ until analysis. Ibuprofen concentrations were determined by HPLC. ${ }^{9}$ Separation was achieved on a pre-packed column (Nova Pak, $5 \mu \mathrm{m}$ RP 18, Waters) with a variable wavelength UV detector. The detection limit of the technique was $<1 \mathrm{mg} / \mathrm{l}$. The intra- and inter-assay errors had a variation coefficient of $<10 \%$.

\section{Population pharmacokinetics analysis}

The serum data were fitted to a one compartment open population model with first order absorption and elimination. The corresponding pharmacokinetic parameters, absorption constant $(\mathrm{Ka})$, elimination clearance $(\mathrm{Cl} / \mathrm{F})$, and apparent distribution volume $(\mathrm{Vd} / \mathrm{F})$ - the latter two normalised by bioavailability (F) —were initially modelled as a function of individual attributes or covariates.

The covariates analysed were continuous (body weight, age, and dose) or categorical (dosage form: ibuprofen lysinate $=0$ /ibuprofen free acid $=1 ;$ and fasting status: fasting $=0 /$ took breakfast half an hour after taking ibuprofen $=1$ ).

The value of the population pharmacokinetics parameters $\mathrm{Ka}, \mathrm{Cl} / \mathrm{F}$, and $\mathrm{Vd} / \mathrm{F}$, the intersubject variability in each parameter $(\eta)$, and the residual errors $(\epsilon)$, that describe the differences between the measured and predicted concentrations were estimated using an extended least squares nonlinear regression method and the WINNONMIX computer program (Pharsight Corporation, California). This program also estimates, for each patient, the individual pharmacokinetic parameters of ibuprofen for the kinetic model employed (Cmax), and the time at which the peak is reached (Tmax).

An exponential error model for interindividual variability and an additive error model for residual variability were assumed.

The criteria used in evaluating alternative models included the difference in objective functions (asymptotically $\chi^{2}$ distributed, $\mathrm{p}<0.001$ being considered to represent a significant improvement in fit), the inspection of weighted residual plots, minimisation of interindividual variances and improvement in their precision, a reduction in the magnitude of the residual variability, and Akaike's information criterion. ${ }^{10}$

\section{RESULTS AND DISCUSSION}

Table 2 shows the final model selected $(p<0.001)$ and the ibuprofen population parameter estimates in children with CF. 
Table 1 Demographic and clinical data of the patients included in the population study

\begin{tabular}{|c|c|}
\hline \multicolumn{2}{|l|}{ Variable } \\
\hline $\begin{array}{l}\text { Sex }(M / F) \\
\text { Age (years) } \\
\text { Body weight }(\mathrm{kg}) \\
\text { Height }(\mathrm{cm}) \\
\text { BMI }\left(\mathrm{kg} / \mathrm{m}^{2}\right) \\
\mathrm{FEV} 1(\%) \\
\text { lbuprofen dosage }(\mathrm{mg} / \mathrm{kg}) \\
\text { IDF (ibuprofen lysinate/ibuprofen } \\
\text { free acid) } \\
\text { Fasting status (fasting/took food) }\end{array}$ & $\begin{array}{l}55 \% / 45 \% \\
9.18(4.08)[2-18]^{*} \\
30.12(12.43)[12-60]^{*} \\
132.20(21.05)[88-177]^{*} \\
17.01(5.17)[4.52-49.51]^{*} \\
83.49(15.26)[51-117]^{*} \\
18.33(4.43)[4-30]^{*} \\
75 \% / 25 \% \\
46 \% / 54 \%\end{array}$ \\
\hline
\end{tabular}

${ }^{*}$ Mean (SD) [range]

$\mathrm{BMI}$, Body mass index; $\mathrm{FEV}_{1}$, forced expiratory volume in one second; IDF, ibuprofen dosage form.

According to the results obtained, ibuprofen pharmacokinetics depend on the weight, dose, type of formulation, and the fasted or fed state of the patient. The influence of these factors accounts for the difficulty encountered by clinicians in maintaining ibuprofen peak concentrations within the therapeutic range.

Most of the pharmacokinetic parameters of ibuprofen estimated with the final population model were obtained with acceptable precision (table 2). However, the interindividual variability of the parameters was excessively high and it was not possible to estimate that corresponding to Ka. In other population studies on ibuprofen, the interindividual variability of the parameters estimated was also high, ${ }^{78}$ even in more homogeneous populations. ${ }^{11}$ The four factors identified here help to explain part of the interindividual variability observed in the pharmacokinetics of ibuprofen, but the high unexplained variability could be due to the heterogeneous clinical status of the patients and the extent of the pharmacokinetic changes due to $\mathrm{CF} .{ }^{1}{ }^{12}{ }^{13}$ In addition, the extent of absorption is unknown for CF patients; changes in the bioavailability (F) of ibuprofen, not quantified in the model, may have occurred due to varying fasting status and dosage form. All this contributes to increasing the variability in clearance and the apparent distribution volume, which in practice are evaluated as $\mathrm{Cl} / \mathrm{F}$ and $\mathrm{Vd} / \mathrm{F}$, respectively.

The results obtained from the final population model point to the existence of dose dependent kinetics of ibuprofen in the paediatric population studied, affecting the clearance and the apparent distribution volume of the drug. These findings are partially in agreement with those reported by other authors, ${ }^{14-16}$ who described the existence of dose dependent kinetics for ibuprofen in adult patients. Likewise, studies in febrile children treated with lower ibuprofen doses (5-10 mg/ $\mathrm{kg}$ ) have not reported modifications in the pharmacokinetic parameters with the dose $\mathrm{e}^{17}$ or modification with low
Table 2 Parameter estimates for the final population model: $\mathrm{Ka}\left(\mathrm{h}^{-1}\right)=\theta_{1}, \mathrm{Cl} / \mathrm{F}(\mathrm{L} / \mathrm{h})=\left(\theta_{2}{ }^{*} \mathrm{~W}+\theta^{3 *} \mathrm{D}\right) *\left(1-\theta_{4}{ }^{*} \mathrm{DDF}\right)$, $\mathrm{Vd} / \mathrm{F}(\mathrm{L})=\left(\theta_{5}{ }^{*} \mathrm{~W}+\theta_{6}{ }^{*} \mathrm{D}\right)^{*}\left(1+\theta_{7}{ }^{*} \mathrm{FS}\right)$

\begin{tabular}{|c|c|c|c|}
\hline Parameter & Estimate & SE $(\%)^{*}$ & $95 \% \mathrm{Cl}$ \\
\hline $\begin{array}{l}\theta_{1} \\
\theta_{2} \\
\theta_{3} \\
\theta_{4} \\
\theta_{5} \\
\theta_{6} \\
\theta_{7} \\
\text { Interindivid } \\
\text { Residual va }\end{array}$ & $\begin{array}{l}6.66 \\
0.07 \\
0.08 \\
0.28 \\
0.10 \\
0.06 \\
0.37 \\
\text { abariabilit } \\
\text { ability: } \sigma^{2} \text { : }\end{array}$ & $\begin{array}{c}31.47 \\
13.70 \\
20.84 \\
22.06 \\
18.98 \\
44.41 \\
45.34 \\
/ \mathrm{F}: 75 \% \text { । } \\
4 \mathrm{mg} / \mathrm{l} / \mathrm{C}\end{array}$ & $\begin{array}{l}2.52 \text { to } 10.80 \\
0.05 \text { to } 0.09 \\
0.05 \text { to } 0.11 \\
0.16 \text { to } 0.41 \\
0.06 \text { to } 0.16 \\
0.01 \text { to } 0.12 \\
2.52 \text { to } 10.80 \\
\text { d/F: } 45 \% \text { (CV) } \\
\text { It }\end{array}$ \\
\hline \multicolumn{4}{|c|}{$\begin{array}{l}\text { W, body weight; D, dose; } \theta \text {, population specific pharmacokinetic } \\
\text { parameter; IDF, ibuprofen dosage form (ibuprofen lysinate = } 0 / \text { ibuprofen } \\
\text { free acid = 1); FS, fasting status (fasting }=0 / \text { food }=1 \text { ). } \\
\text { *Standard error of the estimate expressed as coefficient of variation (\%). } \\
\text { †For a mean concentration of } 38 \mathrm{mg} / \mathrm{l} \text {. }\end{array}$} \\
\hline
\end{tabular}

statistical significance. ${ }^{18} 19$ The significant dose dependence observed here could be due to the use of higher doses for efficacy in CF.

The fasting status also significantly affected the population kinetics of the drug. ${ }^{20}$ In our study, administration of food after the ibuprofen dosing led to an increase in the $\mathrm{Vd} / \mathrm{F}$ ratio of ibuprofen. This suggests the possible occurrence of alterations in the bioavailable fraction of the drug (F) and not in the apparent distribution volume (Vd). Thus, for more stable ibuprofen levels daily maintenance of the same dietary behaviour is advised.

As may be explained from the population model, the type of dosage form significantly affects the $\mathrm{Cl} / \mathrm{F}$ ratio of ibuprofen. The observed reduction in the value of $\mathrm{Cl} / \mathrm{F}$ when the drug is administered in the free acid form could be related to changes in the bioavailable fraction (F). Figure 1 shows that administration of ibuprofen in the free acid form elicits a slower absorption, leading to a reduction in the maximum serum levels and an increase in the time for the maximum concentration to be reached, as has been shown previously in healthy volunteers. ${ }^{5}$ Additionally, the variability in serum levels corresponding to administration of the drug in its free acid form was greater than that observed when it was administered as its lysinate salt. By contrast, our population model does not reflect changes in the first order absorption constant due to the type of formulation used. This can be explained by the reduced use of the formulation corresponding to the free acid form in the population studied. Forty six per cent of the patients were initially treated with ibuprofen free acid, but when the study ended only $25 \%$ of the data corresponded to this form. This was because with the lysinate form lower doses were required and lower variability was observed in Cmax levels. In conclusion, emphasis should be placed on the type of formulation to be used at the start of
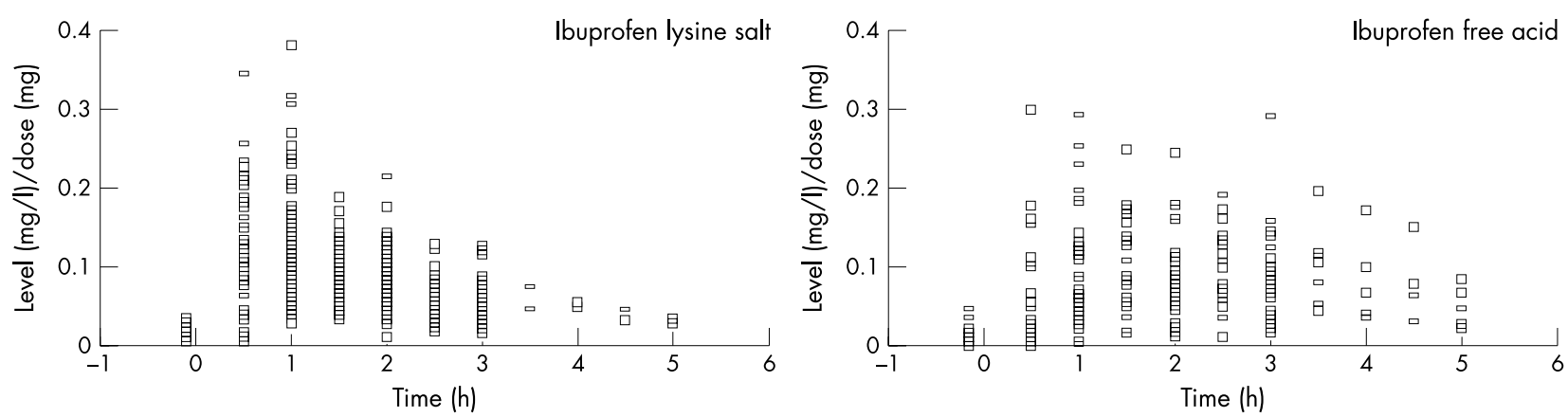

Figure 1 Ibuprofen level/dose ratio versus time for the two dosage forms used in the study. 


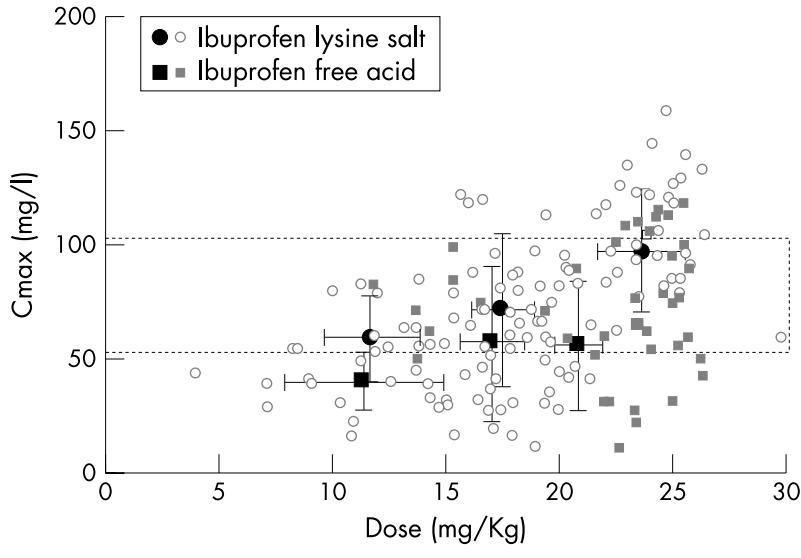

Figure 2 Relation between predicted peak serum concentrations (Cmax) and dose administered for each of the two formulations used (circles: ibuprofen lysine salt, and squares: ibuprofen free acid form). Grey symbols: individual data; black symbols: the mean value (SD) of Cmax for three dose ranges $(<15,15-20$, and $>20 \mathrm{mg} / \mathrm{kg})$.

treatment with ibuprofen. In the light of our results, we suggest the use of the lysinate dosage form of ibuprofen instead of the free acid form.

Figure 2 shows the peak concentrations of ibuprofen predicted with our model for the doses administered to each patient. The figure also shows, for each of the two formulations used, the mean value (SD) of Cmax for the three dose ranges administered $(<15,15-20$, and $>20 \mathrm{mg} /$ $\mathrm{kg}$ ). The individual data first point to the high interindividual variability in ibuprofen pharmacokinetics. As may be seen, the doses administered did not always afford therapeutic concentrations, and continuous adjustment of the dose through therapeutic drug monitoring was required. These data also reveal the lack of proportionality between the doses administered and the Cmax obtained, reflected in the observed dose dependence. Moreover, the mean values show that identification of any factor that affects the pharmacokinetics of the drug (in this case, the type of formulation administered) helps to differentiate the particular situation of each individual patient. When the lysinate salt is used, doses of $15-20 \mathrm{mg} / \mathrm{kg}$ are required for therapeutic levels to be reached in most patients. Doses above $20 \mathrm{mg} / \mathrm{kg}$ are associated with a high occurrence of Cmax values above the therapeutic range. In view of the differences in its pharmacokinetics, on administering ibuprofen in free acid form we found lower concentrations. Accordingly, there is a lower likelihood of toxicity when high doses are administered.

In conclusion, in the clinical use of ibuprofen in children with CF, patient weight, the type of formulation, the ingestion or not of food, and the dose may influence ibuprofen levels, resulting in either toxicity or in subtherapeutic effects. Therapeutic drug monitoring of high dose ibuprofen in CF contributes to its optimal use.

\section{Authors' affiliations}

I Arranz, F Mora, J Mercader, E Ripoll, Biochemical Service, Ramón y Cajal Hospital, Madrid, Spain

A Martín-Suárez, J M Lanao, Department of Pharmacy and

Pharmaceutical Technology, University of Salamanca, Spain

C Vázquez, Paediatric Service, Cruces Hospital, Bilbao, Spain

A Escribano, Paediatric Service, Clínico Hospital, Valencia, Spain

M Juste, Paediatric Service, San Juan Hospital, Alicante, Spain

\section{REFERENCES}

1 Konstan MW, Byard PJ, Hoppel CL, et al. Effect of high dose ibuprofen in cystic fibrosis. N Engl J Med 1995;332:848-54.

2 Kennedy MJ. Inflammation and cystic fibrosis pulmonary disease. Pharmacotherapy 2001;21:593-603.

3 Litalien C, Jacqz-Aigrain E. Risks and benefits of nonsteroidal antiinflammatory drugs in children: a comparison with paracetamol. Paediatr Drugs 2001;3:817-58.

4 Jaffe A, Balfour-Lynn IM. Treatment of severe small airways disease in children with cystic fibrosis: alternatives to corticosteroids. Paediatr Drugs 2002:4:381-9.

5 Geisslinger G, Dietzel K, Bezler $\mathrm{H}$, et al. Therapeutically relevant differences in the pharmacokinetical and pharmaceutical behaviour of ibuprofen lysinate as compared to ibuprofen acid. Int I Clin Pharmacol Ther Toxicol 1989:27:324-8.

6 Konstan MW, Hoppel CL, Chai B, et al. Ibuprofen in children with cystic fibrosis: pharmacokinetics and adverse effects. J Pediatr 1991;118:956-64.

7 Murry DJ, Oermann CM, Ou C-N, et al. Pharmacokinetics of ibuprofen in patients with cystic fibrosis. Pharmacotherapy 1999;19:340-5.

8 Beringer $\mathbf{P}$, Aminimanizani A, Synold T, et al. Development of population pharmacokinetic models and optimal sampling times for ibuprofen tablet and suspension formulations in children with cystic fibrosis. Ther Drug Monit 2002;24:315-21.

9 Rifai N, Sakamoto M, Law T, et al. Use of a rapid HPLC assay for determination of pharmacokinetic parameters of ibuprofen in patients with cystic fibrosis. Clin Chem 1996;42:1812-16.

10 Trocóniz FI, Armenteros S, Planelles MV, et al. Pharmacokineticpharmacodynamic modelling of the antipyretic effect of two oral formulations of ibuprofen. Clin Pharmacokinet 2000;38:505-18.

11 Davidian M, Giltinan DM. Monographs on statistics and applied probability. Vol 62. Nonlinear models for repeated measurement data. London: Chapman \& Hall, 1995.

12 Dong JQ, Ni L, Scott CS, et al. Pharmacokinetics of ibuprofen enantiomers in children with cystic fibrosis. J Clin Pharmacol 2000:40:861-8.

13 Scott CS, Retsch-Bogart GZ, Kustra RP, et al. The pharmacokinetics of ibuprofen suspension, chewable tablets, and tablets in children with cystic fibrosis. J Pediatr 1999;134:58-63.

14 Lockwood GF, Albert KS, Gillespie WR, et al. Pharmacokinetics of ibuprofen in man. I: free and total area/dose relationships. Clin Pharmacol Ther 1983;31:97-103.

15 Albert KS, Gernaat CM. Pharmacokinetics of ibuprofen. Am J Med 1984:23:40-6.

16 Lockwood GF, Albert KS, Szupunar GJ, et al. Pharmacokinetics of ibuprofen in man III: plasma protein binding. J Pharmacokinet Biopharm 1983;11:469-82.

17 Brown RD, Wilson JT, Kearns GL, et al. Single-dose pharmacokinetics of ibuprofen and acetaminophen in febrile children. J Clin Pharmacol 1992;32:231-41.

18 Brown RD, Kearns GL, Wilson JT. Integrated pharmacokineticpharmacodynamic model for acetaminophen, ibuprofen, and placebo antipyresis in children. J Pharmacokin Biopharm 1998;26:559-79.

19 Nahata MC, Durrell DE, Powell DA, et al. Pharmacokinetics of ibuprofen in febrile children. Eur J Clin Pharmacol 1991;40:427-8.

20 Davies NM. Clinical pharmacokinetics of ibuprofen. Clin Pharmacokinet 1998:34:101-54. 